\title{
PARÂMETROS NUTRICIONAIS DE FORRAGEIRAS NATIVAS E EXÓTICAS NO VALE DO ITAJAÍ, SANTA CATARINA ${ }^{1}$
}

\author{
FRANCISCO CARLOSDESCHAMPS² e FERNANDO ADAMI TCACENCO ${ }^{3}$
}

\begin{abstract}
RESUMO - A introdução de espécies exóticas tem sido proposta como alternativa para melhorar a qualidade e a disponibilidade de forragem nas pastagens do Vale do Itajá́, Santa Catarina. O objetivo deste trabalho foi determinar a concentração de proteína bruta (PB) e digestibilidade in vitro da matéria orgânica (DIVMO), como parâmetros de qualidade de 38 acessos de forragens nativas e exóticas, acompanhadas ao longo de três anos, com e sem uso de adubação. As gramíneas exóticas não apresentaram qualidade superior às nativas. A adubação contribuiu para melhorar a qualidade das forragens, já que os teores de PB e DIVMO foram maiores $(\mathrm{P}<0,05)$, para as parcelas adubadas. Na formação de grupos, as características nutricionais não foram uniformes, sendo alguns acessos melhores em PB e outros em DIVMO. Acessos de Paspalum jesuiticum formaram um grupo com teor médio de PB maior que $15 \%$ e DIVMO menor que 53\%. Acessos de Brachiaria formaram outro grupo cujos valores médios de DIVMO foram superiores a $60 \%$ e de PB ficaram abaixo de $12 \%$. Portanto, os teores médios de PB e DIVMO apresentados pelas espécies exóticas não seriam suficientes para justificar a substituição das espécies nativas encontradas nas pastagens do Vale do Itajaí.
\end{abstract}

Termos para indexação: digestibilidade, forragem, gramíneas, pastagem nativa, proteína.

\section{NUTRITIONAL PARAMETERS OF EXOTIC AND NATIVE FORAGE SPECIES OF ITAJAÍ VALLEY, SANTA CATARINA STATE, BRAZIL}

\begin{abstract}
In order to improve the quality and availability of forages in Itajaí Valley, Santa Catarina State, South Brazil, the partial or total substitution of native species has been suggested. This study aimed at determining the concentration of crude protein (CP) and in vitro organic matter digestibility (IVOMD) of thirty-eight accessions of exotic and native forage species, accompanied for a period of three years, with or without fertilization. The exotic grasses did not prove superior to the native accessions. The fertilization affected positively the quality parameters, with the accessions showing improved $(\mathrm{P}<0.05) \mathrm{CP}$ and IVOMD levels as a result of fertilization. Group formation was not possible as a function of different characteristics of forages, with accessions showing higher levels of CP but lower IVOMD. Paspalum jesuiticum made up a group, recording CP content higher than $15 \%$ in contrast to IVOMD lower than 53\%. On the other hand, Brachiaria accessions showed IVOMD higher than $60 \%$ and $\mathrm{CP}$ content lower than $12 \%$. The nutritional parameters involving CP and IVOMD, recorded by exotic accessions, were not enough to justify partial or total substitution of native species found in the pastures of Itajaí Valley.
\end{abstract}

Index terms: digestibility, forages, grass, native pastures, protein.

${ }^{1}$ Aceito para publicação em 8 de fevereiro de 1999

${ }^{2}$ Méd. Vet., D.Sc., EPAGRI S/A, Estação Experimental de Itajaí, Caixa Postal 277, CEP 88301-970 Itajaí, SC. Bolsista do CNPq. E-mail: xicodsc@epagri.rct-sc.br

${ }^{3}$ Eng. Agrôn., Ph.D., EPAGRI S/A.

\section{INTRODUÇÃO}

No Estado de Santa Catarina e em especial no Vale do Itajaí, a exploração da bovinocultura leiteira é conduzida em minifúndios com áreas não 
superiores a 25 ha. A produtividade média dos rebanhos, de pouco mais de $2.000 \mathrm{~L} / \mathrm{vaca} / \mathrm{ano}$, é considerada baixa. Em grande parte, esse resultado é decorrente da baixa qualidade dos volumosos disponíveis para alimentação animal (Seiffert et al., 1990). Nesse sistema, os volumosos que participam da dieta são supridos tanto por capineiras como por pastagem nativa, com destaque para a última. Como forma de melhorar a disponibilidade e qualidade das pastagens utilizadas nos sistemas de produção de leite, tem-se sugerido a introdução de espécies exóticas em complementação ou substituição à pastagem nativa (Pillar \& Tcacenco, 1987; Seiffert et al., 1990). Entretanto, ainda não foi determinado se a introdução de espécies exóticas realmente contribui para melhorar a qualidade das pastagens nativas do ecossistema da região. Tais pastagens também apresentam certa complexidade tanto na sua constituição como nas relações com o ambiente local. Isso foi demonstrado por Pillar \& Tcacenco (1987), ao estudarem 42 áreas de pastagens nativas do Vale do Itajaí e litoral norte de Santa Catarina. Os autores determinaram que a composição das pastagens é bastante diversificada, e os gêneros que apresentaram maior freqüência na cobertura vegetal foram Axonopus (A. obtusifolius, A. affinis, $A$. repens) e Paspalum ( $P$. natatum, $P$. pumilum, $P$. jesuiticum, $P$. conjugatum).

O objetivo deste trabalho foi avaliar a qualidade de espécies forrageiras exóticas e nativas que compõem as pastagens do Vale do Itajaí, SC.

\section{MATERIAL E MÉTODOS}

Foram avaliados 35 acessos de gramíneas, principalmente dos gêneros Paspalum e Axonopus e três acessos de leguminosas do gênero Arachis (Tabela 1). Os materiais foram plantados em parcelas de $2,0 \mathrm{~m} \mathrm{x}$ $8,0 \mathrm{~m}$, sendo metade delas $(2,0 \mathrm{~m} \times 4,0 \mathrm{~m})$ corrigida e adubada por ocasião da implantação, seguindo a recomendação da Rede Oficial de Laboratórios de Análises de Solos dos Estados do Rio Grande do Sul e Santa Catarina. As parcelas não adubadas apresentaram as seguintes características: $\mathrm{pH}\left(\mathrm{H}_{2} 0,1: 1\right)$ 5,1; $\mathrm{pH}$ (SMP) 5,2; $\mathrm{P}$ (Mehlich 1, ppm) 2,2; K (Mehlich 1, ppm) 30; matéria orgânica (\%) 3,1; $\mathrm{Al}\left(\mathrm{KCl} 1 \mathrm{~N}\right.$, meq/100 cm $\left.\mathrm{cm}^{3}\right)$ 2,0; $\mathrm{Ca}+\mathrm{Mg}\left(\mathrm{KCl} 1 \mathrm{~N}\right.$, meq/100 $\left.\mathrm{cm}^{3}\right)$ 7,5; quanto às parcelas adubadas, os valores foram os seguintes: $\mathrm{pH}\left(\mathrm{H}_{2} 0,1: 1\right)$
5,2; pH (SMP) 5,5; P (Mehlich 1, ppm) 4,2; K (Mehlich 1, ppm) 45; matéria orgânica (\%) 3,1; $\mathrm{Al}$ $\left(\mathrm{KCl} 1 \mathrm{~N}\right.$, meq $\left./ 100 \mathrm{~cm}^{3}\right) 1,2 ; \mathrm{Ca}+\mathrm{Mg}\left(\mathrm{KCl} 1 \mathrm{~N}\right.$, meq $\left./ 100 \mathrm{~cm}^{3}\right)$ 8,4 . Não foram realizadas novas adubações ao longo do período de avaliação do ensaio. Os cortes foram feitos a cada 35 dias, abrangendo o período de $2 / 88$ a 12/90, e em cada parcela eram cortados dois quadrados de $0,7 \mathrm{~m}$ de lado, com altura de corte de $2 \mathrm{~cm}$ do solo. Por ocasião do corte, cada quadrado ocupava sempre a mesma posição na parcela. Após o corte, as amostras foram secadas em estufa com ar forçado, à temperatura de $65^{\circ} \mathrm{C}$, durante 72 horas. Logo após, o material foi moído em moinho tipo Willey, dotado de peneira de $1 \mathrm{~mm}$, para posterior análise. Foram determinados o teor de matéria orgânica e cinzas a partir da incineração das amostras; teor de proteína bruta (PB), determinado como $\mathrm{N}$ x 6,25 pelo método de Kjeldahl. Foi determinado também o percentual de digestibilidade da matéria orgânica (DIVMO), utilizando-se a técnica de dois estágios descrita por Tilley \& Terry (1963). As análises foram conduzidas no Laboratório de Nutrição Animal da EPAGRI - Estação Experimental de Lages, SC. Os resultados das análises foram agrupados por estação do ano, sendo submetidos à análise de variância e teste de médias quanto aos principais fatores. O teste de agrupamentos de Scott-Knott e de conglomerados (Cluster) foram utilizados como complementares para a comparação das médias de PB e DIVMO.

\section{RESULTADOS E DISCUSSÃO}

O desempenho produtivo dos ruminantes apresenta estreita relação com a qualidade da dieta consumida. As forragens, como alimentos preferenciais desses animais, devem, portanto, apresentar a melhor qualidade possível. Os resultados dos parâmetros de qualidade abordados neste trabalho (PB e DIVMO) estão apresentados nas Tabelas 2 e 3. A análise conjunta dos dados, tendo ano, época do ano e adubação como fatores, permitiu detectar algumas tendências interessantes. Em todos os três fatores avaliados houve diferenças $(\mathrm{P}<0,05)$ nos parâmetros de qualidade em estudo. $\mathrm{O}$ teor de PB diminuiu com o avanço do tempo ao longo do período de avaliação, sendo de $14,4 \%$ no ano 1 , e 13,3 e 12,7\% nos dois anos subseqüentes. Já a DIVMO foi superior apenas no ano $1(58,1 \%)$, não diferindo nos demais (55,3 e 55,8\%). Com relação à estação do ano, tanto a PB quanto a DIVMO apresentaram médias com diferença estatística significati- 
TABELA 1. Lista dos acessos de plantas forrageiras exóticas e nativas utilizadas no presente trabalho.

\begin{tabular}{|c|c|c|c|c|}
\hline Acesso & № EEI & Nome científico & Cultivar ou coleta & Origem \\
\hline 008 & 85255 & Arachis pintoii & CPAC & \\
\hline 009 & 85009 & Arachis repens & Janaúba & \\
\hline 010 & 88005 & Arachis repens & $\mathrm{CPAC}$ & \\
\hline 156 & 87015 & Axonopus affinis & Comercial & \\
\hline 131 & 1416 & Brachiaria dictioneura & CNPGL 578-76 & \\
\hline 151 & 1416 & Brachiaria dictioneura & CNPGL 578-76 & \\
\hline 146 & 1130 & Brachiaria humidicola & IRI & \\
\hline 200 & 1130 & Brachiaria humidicola & IRI & \\
\hline 139 & 85011 & Cynodon dactylon & Colonial 1 & \\
\hline 130 & 1183 & Digitaria pentzii & Pangola & \\
\hline 150 & 1183 & Digitaria pentzii & Pangola & \\
\hline 155 & 87014 & Paspalum saurae & Pensacola & \\
\hline 207 & 87014 & Paspalum saurae & Pensacola & \\
\hline 206 & 88014 & Pennisetum clandestinum & Lages, SC & \\
\hline 138 & 86024 & Axonopus obtusifolius & Coleta Tcacenco 018 & C. Tiedt, Luiz Alves, SC \\
\hline 140 & 86019 & Axonopus obtusifolius & Coleta Tcacenco 011 & N. Zinnke, Pomerode, SC \\
\hline 141 & 86021 & Axonopus obtusifolius & Coleta Tcacenco 014 & W. Muller, Blumenau, SC \\
\hline 142 & 86026 & Axonopus obtusifolius & Coleta Tcacenco 022 & C. Tiedt, Luiz Alves, SC \\
\hline 148 & 2054 & Axonopus obtusifolius & Coleta Salerno/Jaques & Alto Vale do Itajaí, SC \\
\hline 153 & 88002 & Axonopus obtusifolius & Coleta Tcacenco 028 & Empasc - EEI, Itajaí, SC \\
\hline 147 & 87005 & Axonopus sp. & Coleta Tcacenco 026 & C. Tiedt, Luiz Alves, SC \\
\hline 149 & 85269 & Axonopus sp. & Coleta Tcacenco/Ramos 037 & Rio do Oeste, $\mathrm{SC}$ \\
\hline 154 & 88003 & Axonopus sp. & Coleta Tcacenco 029 & Empasc - EEI, Itajaí, SC \\
\hline 196 & 89028 & Axonopus sp. & Coleta Tcacenco/Vetterle 048 & A. Danzer, Dona Ema, SC \\
\hline 197 & 89009 & Axonopus sp. & Coleta Tcacenco/Ramos 046 & Presidente Getúlio, SC \\
\hline 201 & 89004 & Axonopus sp. & Roxa & Ituporanga, SC \\
\hline 129 & 89005 & Panicum sp. & Coleta Tcacenco 034 & Empasc - EEI, Itajaí, SC \\
\hline 152 & 88001 & Paspalum conjugatum & Coleta Tcacenco 027 & Empasc - EEI, Itajaí, SC \\
\hline 128 & 85270 & Paspalum jesuiticum & Coleta Tcacenco 006 & Empasc - EEI, Itajaí, SC \\
\hline 134 & 86016 & Paspalum jesuiticum & Coleta Tcacenco 007 & W. Müller, Blumenau, SC \\
\hline 135 & 86020 & Paspalum jesuiticum & Coleta Tcacenco 012 & N. Zinnke, Pomerode, SC \\
\hline 136 & 86023 & Paspalum jesuiticum & Coleta Tcacenco 016 & C. Tied, Luiz Alves, SC \\
\hline 137 & 86025 & Paspalum jesuiticum & Coleta Tcacenco 021 & C. Tied, Luiz Alves, SC \\
\hline 199 & 89003 & Paspalum notatum & Coleta Tcacenco 033 & Empasc - EEI, Itajaí, SC \\
\hline 143 & 86017 & Paspalum pumilum & Coleta Tcacenco 008 & W. Müller, Blumenau, SC \\
\hline 144 & 86018 & Paspalum pumilum & Coleta Tcacenco 009 & W. Müller, Blumenau, SC \\
\hline 145 & 86022 & Paspalum pumilum & Coleta Tcacenco 015 & W. Müller, Blumenau, SC \\
\hline 198 & 89002 & Paspalum pumilum & Coleta Tcacenco 032 & Empasc - EEI, Itajaí, SC \\
\hline
\end{tabular}


TABELA 2. Porcentagem média (três anos) de proteína bruta $(\mathrm{N} \times$ 6,25) dos acessos de forrageiras exóticas e nativas, de acordo com o nível de adubação e a estação do ano.

\begin{tabular}{|c|c|c|c|c|c|c|c|c|c|c|}
\hline \multirow[t]{2}{*}{ Acesso } & \multicolumn{5}{|c|}{ Com adubação } & \multicolumn{5}{|c|}{ Sem adubação } \\
\hline & Verão & Outono & Inverno & Primavera & Média & Verão & Outono & Inverno & Primavera & Média \\
\hline 008 & 23,0 & 18,6 & 21,4 & 19,7 & 20,7 & 20,7 & 19,1 & 19,6 & 12,8 & 18,1 \\
\hline 009 & 20,8 & 18,4 & 23,0 & 20,8 & 20,8 & 18,5 & 16,3 & 18,2 & 18,5 & 17,9 \\
\hline 010 & 22,3 & 24,5 & 26,4 & 24,4 & 24,4 & 19,4 & 21,6 & 20,8 & 21,4 & 20,8 \\
\hline Média & 21,6 & 21,5 & 24,7 & 22,6 & 22,6 & 19,0 & 19,0 & 19,5 & 20,0 & 19,3 \\
\hline 156 & 12,2 & 15,6 & 18,8 & 12,4 & 14,8 & 9,2 & 10,5 & 10,1 & 10,2 & 10,0 \\
\hline 131 & 10,8 & 12,0 & 15,0 & 9,6 & 11,9 & 8,8 & 8,9 & 11,0 & 8,4 & 9,3 \\
\hline 151 & 11,1 & 14,1 & 15,2 & 10,2 & 12,7 & 6,6 & 11,7 & 11,6 & 11,3 & 10,3 \\
\hline Média & 11,0 & 13,1 & 15,1 & 9,9 & 12,3 & 7,7 & 10,3 & 11,3 & 9,9 & 9,8 \\
\hline 146 & 14,1 & 14,0 & 14,4 & 11,4 & 13,5 & 11,1 & 11,3 & 13,3 & 10,0 & 11,4 \\
\hline 200 & 15,0 & 15,5 & 17,4 & 12,8 & 15,2 & 11,9 & 13,4 & 14,5 & 9,6 & 12,4 \\
\hline Média & 14,6 & 14,8 & 15,9 & 12,1 & 14,3 & 11,5 & 12,4 & 13,9 & 9,8 & 11,9 \\
\hline 139 & 13,4 & 14,1 & 18,5 & 12,1 & 14,5 & 13,3 & 14,8 & 15,6 & 13,2 & 14,2 \\
\hline 130 & 11,4 & 12,0 & 17,4 & 11,9 & 13,2 & 8,3 & 10,8 & 10,3 & 9,5 & 9,7 \\
\hline 150 & 11,6 & 14,1 & 19,3 & 12,3 & 14,3 & 9,0 & 11,8 & 15,4 & 12,8 & 12,3 \\
\hline Média & 11,5 & 13,1 & 18,4 & 12,1 & 13,8 & 8,7 & 11,3 & 12,9 & 11,2 & 11,0 \\
\hline 155 & 13,4 & 13,1 & 16,1 & 12,0 & 13,7 & 9,3 & 11,0 & 10,8 & 10,2 & 10,3 \\
\hline 207 & 12,7 & 13,6 & 15,4 & 12,6 & 13,6 & 8,8 & 10,1 & 10,6 & 11,6 & 10,3 \\
\hline Média & 13,1 & 13,4 & 15,8 & 12,3 & 13,6 & 9,1 & 10,6 & 10,7 & 10,9 & 10,3 \\
\hline 206 & 12,5 & 17,0 & 18,7 & 12,0 & 15,1 & 11,9 & 12,3 & 12,4 & 9,4 & 11,5 \\
\hline 138 & 13,8 & 14,3 & 15,2 & 12,4 & 13,9 & 13,3 & 13,7 & 12,3 & 12,2 & 12,9 \\
\hline 140 & 16,9 & 16,3 & 16,4 & 12,6 & 16,2 & 13,1 & 13,7 & 12,8 & 12,9 & 13,1 \\
\hline 141 & 15,7 & 16,0 & 17,0 & 12,7 & 15,4 & 14,0 & 13,1 & 12,1 & 11,0 & 12,6 \\
\hline 142 & 16,2 & 16,0 & 16,2 & 11,9 & 15,1 & 12,7 & 12,5 & 13,3 & 11,6 & 12,5 \\
\hline 148 & 14,4 & 14,9 & 16,4 & 13,0 & 14,7 & 8,0 & 11,5 & 14,1 & 11,1 & 11,2 \\
\hline 153 & 12,7 & 15,0 & 16,7 & 14,3 & 14,7 & 9,5 & 10,1 & 13,3 & 12,2 & 11,2 \\
\hline Média & 15,4 & 15,4 & 16,3 & 12,8 & 15,0 & 11,8 & 12,4 & 13,0 & 11,8 & 12,2 \\
\hline 147 & 13,6 & 14,5 & 14,5 & 10,9 & 13,4 & 11,1 & 10,5 & 12,1 & 10,5 & 11,1 \\
\hline 149 & 12,8 & 15,0 & 15,2 & 10,7 & 13,4 & 9,0 & 12,9 & 13,1 & 11,9 & 11,7 \\
\hline 154 & 14,0 & 13,9 & 13,6 & 11,7 & 13,3 & 8,3 & 10,3 & 11,1 & 12,3 & 10,5 \\
\hline 196 & 12,2 & 12,2 & 15,5 & --- & 13,3 & 11,4 & 10,5 & 10,0 & 8,8 & 10,2 \\
\hline 197 & 10,5 & 11,5 & 14,6 & 9,6 & 12,3 & 8,5 & 10,1 & 10,5 & 8,3 & 9,4 \\
\hline 201 & 14,2 & 16,9 & 20,1 & 12,6 & 13,9 & 12,2 & 14,4 & 13,9 & 10,1 & 12,7 \\
\hline Média & 12,9 & 14,0 & 15,6 & 11,1 & 13,3 & 10,1 & 11,5 & 11,8 & 10,3 & 10,9 \\
\hline 129 & 14,3 & 16,0 & 17,3 & 10,9 & 14,7 & 10,6 & 10,0 & 10,6 & 11,4 & 10,7 \\
\hline 152 & 11,8 & 13,7 & 14,7 & 11,2 & 12,9 & 9,7 & 14,0 & 10,0 & 13,0 & 11,7 \\
\hline 128 & 15,3 & 15,6 & 18,1 & 13,1 & 15,5 & 12,4 & 14,0 & 16,3 & 16,0 & 14,7 \\
\hline 134 & 16,2 & 18,0 & 19,2 & 15,6 & 17,3 & 14,4 & 15,4 & 16,2 & 12,0 & 14,5 \\
\hline 135 & 16,7 & 17,9 & 18,5 & 15,4 & 17,1 & 15,2 & 16,2 & 17,4 & 14,2 & 15,8 \\
\hline 136 & 15,1 & 17,5 & 19,2 & 15,6 & 16,9 & 13,5 & 15,1 & 16,2 & 14,9 & 14,9 \\
\hline 137 & 15,9 & 17,3 & 17,7 & 15,1 & 16,5 & 11,7 & 13,3 & 16,0 & 14,3 & 13,8 \\
\hline Média & 15,8 & 17,3 & 18,5 & 15,0 & 16,7 & 13,4 & 14,8 & 16,4 & 14,3 & 14,7 \\
\hline 199 & 15,1 & 13,0 & 17,5 & 13,0 & 14,7 & 15,1 & 10,5 & 14,1 & 11,1 & 12,7 \\
\hline 143 & 13,1 & 12,3 & 14,6 & 10,8 & 12,7 & 11,2 & 14,1 & 11,9 & 10,1 & 11,8 \\
\hline 144 & 13,4 & 13,0 & 15,2 & 11,1 & 13,2 & 10,1 & 9,8 & 11,6 & 10,2 & 10,4 \\
\hline 145 & 12,6 & 13,5 & 14,6 & 11,6 & 13,1 & 9,8 & 10,0 & 12,0 & 10,5 & 10,6 \\
\hline 198 & 11,8 & 11,6 & 16,9 & 10,8 & 12,8 & 11,7 & 9,1 & 15,6 & 9,2 & 11,4 \\
\hline Média & 12,7 & 12,6 & 15,3 & 11,1 & 12,9 & 10,7 & 10,8 & 12,8 & 10,0 & 11,1 \\
\hline
\end{tabular}


TABELA 3. Digestibilidade (DIVMO - \% média três anos) dos acessos de forrageiras exóticas e nativas, de acordo com o nível de adubação e a estação do ano.

\begin{tabular}{|c|c|c|c|c|c|c|c|c|c|c|}
\hline \multirow[t]{2}{*}{ Acesso } & \multicolumn{5}{|c|}{ Com adubação } & \multicolumn{5}{|c|}{ Sem adubação } \\
\hline & Verão & Outono & Inverno & Primavera & Média & Verão & Outono & Inverno & Primavera & $\overline{\text { Média }}$ \\
\hline 008 & 67,2 & 65,5 & 68,8 & 70,5 & 68,0 & 64,0 & 60,1 & 56,0 & 61,0 & 60,3 \\
\hline 009 & 67,7 & 65,2 & 64,4 & 72,1 & 67,4 & 64,4 & 61,5 & 53,4 & 63,4 & 60,7 \\
\hline 010 & 65,7 & 64,7 & 60,6 & 67,5 & 64,6 & 66,1 & 61,3 & 57,5 & 64,5 & 62,4 \\
\hline Média & 66,7 & 65,0 & 62,5 & 69,8 & 66,0 & 65,3 & 61,4 & 55,5 & 64,0 & 61,5 \\
\hline 156 & 58,2 & 54,0 & 60,0 & 56,5 & 57,2 & 56,5 & 54,4 & 53,1 & 59,2 & 55,8 \\
\hline 131 & 61,8 & 64,1 & 61,1 & 71,4 & 64,6 & 66,5 & 58,3 & 61,9 & 67,3 & 63,5 \\
\hline 151 & 61,2 & 63,8 & 68,4 & 66,4 & 65,0 & 64,5 & 60,2 & 63,3 & 66,7 & 63,7 \\
\hline Média & 61,5 & 63,9 & 64,8 & 68,9 & 64,8 & 65,5 & 59,3 & 62,6 & 67,0 & 63,6 \\
\hline 146 & 64,2 & 64,0 & 61,0 & 63,3 & 63,1 & 64,5 & 56,1 & 56,5 & 66,3 & 60,9 \\
\hline 200 & 68,7 & 54,0 & 58,7 & 57,8 & 59,8 & 60,0 & 57,0 & 59,3 & 58,8 & 58,8 \\
\hline Média & 66,5 & 59,0 & 59,9 & 60,6 & 61,5 & 62,3 & 56,6 & 57,9 & 62,6 & 59,8 \\
\hline 139 & 55,0 & 54,6 & 60,0 & 58,0 & 56,9 & 58,1 & 55,1 & 59,0 & 54,2 & 56,6 \\
\hline 130 & 62,4 & 54,4 & 56,3 & 72,6 & 61,4 & 64,1 & 53,9 & 47,0 & 60,2 & 56,3 \\
\hline 150 & 59,5 & 54,7 & 67,4 & 68,8 & 62,6 & 65,9 & 53,2 & 59,5 & 66,3 & 61,2 \\
\hline Média & 61,0 & 54,6 & 61,9 & 70,7 & 62,0 & 65,0 & 53,6 & 53,3 & 63,3 & 58,8 \\
\hline 155 & 63,1 & 54,5 & 55,3 & 56,5 & 57,4 & 56,8 & 49,4 & 44,5 & 59,2 & 52,5 \\
\hline 207 & 57,5 & 50,9 & 53,8 & 49,3 & 52,9 & 56,8 & 50,6 & 44,0 & 51,1 & 50,6 \\
\hline Média & 60,3 & 52,7 & 54,6 & 52,9 & 55,1 & 56,8 & 50,0 & 44,3 & 55,2 & 51,6 \\
\hline 206 & 58,9 & 54,4 & 60,0 & 58,2 & 57,9 & 48,8 & 57,6 & 57,9 & 61,3 & 56,4 \\
\hline 138 & 58,7 & 57,1 & 56,3 & 50,3 & 55,6 & 51,0 & 46,0 & 53,8 & 53,0 & 51,0 \\
\hline 140 & 59,0 & 55,8 & 56,0 & 52,5 & 55,8 & 53,2 & 49,3 & 49,0 & 48,0 & 49,9 \\
\hline 141 & 58,0 & 53,2 & 62,6 & 56,2 & 57,5 & 63,8 & 51,0 & 49,3 & 50,5 & 53,7 \\
\hline 142 & 56,3 & 57,6 & 60,1 & 55,6 & 57,4 & 49,8 & 46,9 & 45,9 & 51,0 & 48,4 \\
\hline 148 & 52,3 & 57,6 & 59,8 & 45,6 & 53,8 & 52,7 & 57,7 & 57,5 & 53,8 & 51,3 \\
\hline 153 & 65,7 & 52,3 & 59,2 & 57,2 & 58,6 & 50,5 & 47,6 & 55,7 & 60,0 & 53,5 \\
\hline Média & 58,3 & 55,6 & 59,0 & 52,9 & 56,4 & 53,5 & 47,0 & 51,9 & 52,7 & 51,3 \\
\hline 147 & 51,6 & 49,6 & 47,5 & 50,6 & 49,8 & 48,7 & 46,3 & 47,7 & 52,3 & $\overline{47,1}$ \\
\hline 149 & 69,8 & 63,4 & 69,5 & 65,3 & 67,0 & 70,4 & 58,1 & 58,3 & 60,0 & 61,7 \\
\hline 154 & 65,5 & 56,7 & 63,7 & 59,3 & 61,3 & 56,3 & 48,6 & 55,7 & 57,2 & 54,5 \\
\hline 196 & 68,6 & 61,7 & 65,7 & 54,2 & 64,7 & 70,7 & 68,7 & 59,9 & 55,1 & 63,6 \\
\hline 197 & 67,4 & 65,2 & 69,7 & --- & 67,4 & 69,3 & 73,0 & 58,5 & 46,8 & 61,9 \\
\hline 201 & 53,2 & 40,0 & 59,3 & 58,1 & 51,6 & 60,3 & 46,8 & 53,5 & 57,8 & 52,1 \\
\hline Média & 62,7 & 56,1 & 62,6 & 57,5 & 60,3 & 62,6 & 55,8 & 55,6 & 53,2 & 56,8 \\
\hline 129 & 61,5 & 59,4 & 59,7 & 64,5 & 61,3 & 60,0 & 50,7 & 51,9 & 60,7 & 55,8 \\
\hline 152 & 62,3 & 63,8 & 61,2 & 64,0 & 62,8 & 61,0 & 55,3 & 56,3 & 58,0 & 57,7 \\
\hline 128 & 53,6 & 46,9 & 54,2 & 56,6 & 52,8 & 54,4 & 48,5 & 44,5 & 46,6 & 48,5 \\
\hline 134 & 53,1 & 52,1 & 56,7 & 56,5 & 54,6 & 55,0 & 47,9 & 52,0 & 52,3 & 51,8 \\
\hline 135 & 53,5 & 48,0 & 58,7 & 57,2 & 54,4 & 50,6 & 47,1 & 54,3 & 50,8 & 50,7 \\
\hline 136 & 49,0 & 49,5 & 55,2 & 56,2 & 52,5 & 50,2 & 45,2 & 52,9 & 51,4 & 49,9 \\
\hline 137 & 51,5 & 48,6 & 55,9 & 52,0 & 52,0 & 49,7 & 44,2 & 54,1 & 56,6 & 51,2 \\
\hline Média & 52,1 & 49,0 & 56,1 & 55,7 & 53,3 & 52,0 & 46,6 & 51,6 & 51,5 & 50,4 \\
\hline 199 & 47,9 & 36,0 & 38,0 & 48,3 & 42,6 & 47,4 & 46,0 & 38,1 & 48,8 & 45,1 \\
\hline 143 & 51,5 & 46,0 & 52,1 & 51,5 & 50,3 & 51,6 & 47,1 & 46,2 & 51,3 & $\overline{49,1}$ \\
\hline 144 & 60,8 & 54,3 & 58,0 & 53,7 & 56,7 & 56,1 & 51,7 & 52,8 & 54,9 & 53,9 \\
\hline 145 & 58,3 & 56,4 & 58,5 & 56,8 & 57,5 & 57,4 & 50,0 & 59,4 & 59,8 & 56,7 \\
\hline 198 & 57,5 & 55,8 & 53,9 & 57,3 & 56,1 & 61,1 & 61,1 & 51,1 & 54,3 & 56,9 \\
\hline Média & 57,0 & 53,1 & 55,6 & 54,8 & 55,2 & 56,6 & 52,5 & 52,4 & 55,1 & 54,1 \\
\hline
\end{tabular}


va $(\mathrm{P}<0,05)$. A maior média de PB $(15,2 \%)$ foi observada nos cortes correspondentes ao inverno, enquanto na primavera observou-se a menor média $12,3 \%(\mathrm{P}<0,05)$. Essa tendência não se repetiu nos dados de DIVMO, cuja melhor média foi observada no verão $(58,1 \%)$, e a pior, no outono $(55,0 \%)$. A associação da freqüência de cortes, que neste trabalho foi de 35 dias, com as condições climáticas do período do ano em que os cortes foram realizados, pode estar relacionada com os resultados obtidos. Nesses termos, é possível que a dinâmica de crescimento das espécies envolvendo número de afilhos, número de folhas, índice de área foliar, relação colmo:folha entre outros, possa, pelo menos em parte, explicar os resultados (Hodgson \& Ollerenshaw, 1969; Chapman \& Lemaire, 1993; Mazzanti et al., 1994; Lemaire, 1997).

A utilização da adubação foi uma prática favorável aos parâmetros qualitativos das forragens. Mesmo sendo usada somente na fase de instalação do ensaio, exerceu efeitos significativos nos teores de PB e DIVMO. Quanto às forragens plantadas nas parcelas adubadas, o teor médio de $\mathrm{PB}$ foi de $14,9 \%$, e a DIVMO foi de $58,2 \%$, contra 12,4 e $55,1 \%$ das não adubadas $(\mathrm{P}<0,05)$. Embora tais diferenças, em termos absolutos, possam ser consideradas pequenas, a utilização da adubação significou um incremento de 20,2\% em PB, e de 5,6\% em DIVMO. Dessa forma, observa-se que os efeitos da adubação se expressaram mais fortemente no teor de PB. Entretanto, uma análise mais detalhada dos resultados permite observar que alguns materiais apresentaram comportamento bastante distinto. Por exemplo, entre as nativas parece que os acessos de Axonopus foram mais sensíveis aos efeitos da adubação, principalmente observados nos teores de PB dos materiais. Nesse caso, as parcelas adubadas apresentaram, em média, 21,6\% a mais de PB que as parcelas não adubadas, enquanto nos acessos de Paspalum, essa diferença foi de cerca de $14,7 \%$. No caso das exóticas, como os acessos de Brachiaria dictioneura (131-151), Digitaria (130-150) e Pensacola (155-207), os efeitos foram ainda maiores quando as diferenças atingiram níveis superiores a $25 \%$. Por outro lado, ao se comparar exóticas e nativas, observa-se que a diferença entre os teores de PB pode ser considerada pequena (Tabela 2).
É importante observar que os efeitos da adubação foram mais expressivos sobre o teor de PB do que sobre a DIVMO, tanto nos acessos das espécies exóticas quanto das nativas. Tcacenco (1994), já havia relatado que a adubação exerceu papel fundamental sobre a produção de MS. O autor relatou que muitos dos acessos de nativas cultivados com adubação, apresentaram em média, acima de duas vezes a produção de MS apresentada pelos materiais não adubados. Dessa maneira, parece claro que as pastagens nativas apresentam um amplo potencial de resposta, tanto em termos de produção quanto de qualidade de MS, a partir da utilização de fertilizantes.

Cabe ressaltar que essa área precisa ser melhor estudada, já que as diferentes espécies podem não responder com a mesma intensidade, em face da adoção dessa prática.

Deve-se lembrar que a adubação, principalmente com $\mathrm{N}$, exerce um papel fundamental na dinâmica de crescimento dos tecidos, aumentando o tamanho das folhas, a taxa de rebrota e alterando a relação caule:folha (Nelson \& Moser, 1994). Nesse sentido, para que se obtenha o ganho de qualidade desejado, na forrageira ou pastagem de interesse, é preciso que haja renovação dos tecidos, seja por pastejo, seja por corte (Nelson \& Moser, 1994). Caso contrário, a taxa de brotação tende a se reduzir, já que a expansão das folhas reduz a disponibilidade de luz para o crescimento dos tecidos basais (Nelson \& Moser, 1994).

Deve-se considerar que a expressão do potencial produtivo das pastagens nativas deve levar em consideração práticas de manejo que envolvam solo, pastagem e animais. Nesse sentido, parece que o conceito de oferta de forragem pode ser determinante para maximizar a produção animal e assegurar uma condição de sustentabilidade à pastagem (Almeida, 1997). De qualquer forma, a aplicação do conceito está intimamente ligada à qualidade da forragem.

Por outro lado, a qualidade e disponibilidade de forragem nos sistemas criatórios determina a expressão do potencial produtivo dos animais. Assim, para o máximo consumo e produção, é desejável que a dieta dos ruminantes apresente digestibilidade próxima aos $70 \%$ e seja adequada em 
proteína e energia (Conrad et al., 1964). Admite-se que é difícil reunir esses requisitos única e exclusivamente alimentando os animais com forragens e principalmente com forragens tropicais. A adição de concentrados torna-se, portanto, a alternativa disponível para dotar a dieta com os parâmetros desejáveis de qualidade. Outra alternativa para melhorar a qualidade da dieta à base de forragens, seria a de aumentar a participação das leguminosas na composição das pastagens. No presente estudo, os acessos de Arachis foram os únicos materiais que apresentaram valores médios elevados para os dois parâmetros de qualidade considerados (Tabelas 2 e 3 ).

Entre as gramíneas exóticas, somente os acessos de Brachiaria e a Digitaria apresentaram digestibilidade média ao redor dos $60 \%$. Entre as nativas, os acesso de Axonopus alcançaram tal percentual de digestão, demonstrando que, independentemente de exóticas ou nativas, a qualidade nutricional dos acessos apresenta limitações para o que seria considerado ideal para atender à fisiologia dos ruminantes. Tal fato pôde ser observado quando se tentou agrupar os acessos, de acordo com os níveis de qualidade dos parâmetros estudados, ou seja, acessos que apresentassem valores elevados tanto em relação à $\mathrm{PB}$ quanto em relação à DIVMO (Tabela 4). Nesse caso, as características nutricionais não foram constantes, pois alguns acessos foram melhores em PB, e outros, em DIVMO. Isso foi confirmado pela análise de correlação entre esses fatores, cujo coeficiente foi de $0,16(\mathrm{P}<0,05)$. Assim, os acessos de $P$. jesuiticum (128-134-135-136-137) formaram um grupo distinto para proteína com elevado teor de PB (Grupo C), enquanto foram baixo em DIVMO (Grupo D). Por outro lado, a Brachiaria (131-151) apresentou boa DIVMO (Grupo A) e baixa PB (Grupo F) (Tabela 4). Existe, portanto, muita dificuldade em fazer grupos distintos entre exóticas e nativas quanto aos parâmetros de qualidade estudados. Isso foi confirmado, posteriormente, pela análise de "cluster". Portanto, os acessos que apresentaram elevados valores de $\mathrm{PB}$ não se comportaram da mesma maneira em relação à DIVMO, o que demonstra certa independência entre os parâmetros. A situação em que tanto os teores de proteína quanto os coeficientes de digestibilidade foram elevadas, somente foi verdadeira para acessos de Arachis. Pode-se observar, com isso, que as leguminosas apresentam um padrão de qualidade

TABELA 4. Teste de agrupamento de Scott-Knott para as variáveis proteína bruta $(\mathrm{PB}) \mathrm{e}$ digestibilidade in vitro da matéria orgânica (DIVMO), das plantas forrageiras exóticas e nativas utilizadas no presente trabalho.

\begin{tabular}{|c|c|c|c|c|c|}
\hline \multicolumn{3}{|c|}{ Proteína bruta (PB) } & \multicolumn{3}{|c|}{$\begin{array}{c}\text { Digestibilidade in vitro } \\
\text { (DIVMO) }\end{array}$} \\
\hline Acesso & Média & Grupo $^{1}$ & Acesso & Média & Grupo ${ }^{1}$ \\
\hline 10 & 22,6 & A & 9 & 64,7 & A \\
\hline 8 & 19,4 & B & 197 & 64,7 & A \\
\hline 9 & 19,2 & B & 151 & 64,3 & A \\
\hline 135 & 16,3 & C & 131 & 64,3 & A \\
\hline 136 & 15,8 & $\mathrm{C}$ & 8 & 64,1 & A \\
\hline 134 & 15,6 & C & 149 & 63,8 & A \\
\hline 137 & 15,1 & $\mathrm{C}$ & 10 & 63,5 & A \\
\hline 128 & 15,0 & $\mathrm{C}$ & 196 & 63,1 & A \\
\hline 140 & 14,3 & D & 146 & 62,3 & A \\
\hline 139 & 14,1 & D & 150 & 61,7 & A \\
\hline 199 & 14,0 & D & 152 & 60,2 & B \\
\hline 201 & 13,9 & D & 200 & 59,3 & B \\
\hline 141 & 13,9 & $\mathrm{D}$ & 130 & 58,4 & B \\
\hline 200 & 13,8 & D & 129 & 58,0 & C \\
\hline 142 & 13,7 & D & 154 & 57,9 & C \\
\hline 206 & 13,2 & E & 145 & 57,0 & C \\
\hline 150 & 13,2 & E & 198 & 56,9 & $\mathrm{C}$ \\
\hline 153 & 13,0 & E & 139 & 56,5 & C \\
\hline 138 & 12,9 & E & 153 & 56,3 & $\mathrm{C}$ \\
\hline 129 & 12,9 & E & 206 & 55,9 & C \\
\hline 148 & 12,9 & E & 156 & 55,8 & $\mathrm{C}$ \\
\hline 149 & 12,6 & E & 141 & 55,5 & C \\
\hline 156 & 12,4 & E & 148 & 55,5 & C \\
\hline 152 & 12,4 & E & 144 & 55,3 & $\mathrm{C}$ \\
\hline 146 & 12,3 & E & 155 & 55,0 & C \\
\hline 147 & 12,1 & $\mathrm{~F}$ & 201 & 54,6 & $\mathrm{C}$ \\
\hline 155 & 12,0 & $\mathrm{~F}$ & 134 & 53,1 & $\mathrm{D}$ \\
\hline 143 & 11,9 & F & 138 & 53,1 & D \\
\hline 207 & 11,8 & $\mathrm{~F}$ & 142 & 52,9 & D \\
\hline 154 & 11,7 & F & 140 & 52,8 & D \\
\hline 198 & 11,7 & $\mathrm{~F}$ & 135 & 52,2 & D \\
\hline 145 & 11,7 & F & 207 & 51,8 & D \\
\hline 144 & 11,6 & $\mathrm{~F}$ & 137 & 51,3 & D \\
\hline 130 & 11,6 & $\mathrm{~F}$ & 136 & 51,1 & D \\
\hline 151 & 11,5 & $\mathrm{~F}$ & 128 & 50,9 & D \\
\hline 196 & 11,5 & F & 147 & 49,9 & D \\
\hline 197 & 10,4 & F & 143 & 49,7 & D \\
\hline 131 & 10,3 & F & 199 & 44,2 & E \\
\hline
\end{tabular}


diferenciado das gramíneas. Além disso, nenhum dos acessos de gramíneas apresentaram parâmetros de qualidade comparáveis ao desejável, o que significa que a consorciação de espécies em uma pastagem ainda constitui-se numa estratégia interessante para compor uma dieta de elevada qualidade nutricional. Assim, foi possível observar que os acessos de espécies exóticas não apresentaram características de qualidade marcadamente superiores às nativas (exceto o Arachis). Em princípio, parece que não é suficiente a proposição de substituição parcial ou total das pastagens nativas por exóticas no âmbito do Vale do Itajaí e litoral norte de Santa Catarina, tendo apenas a qualidade em PB e DIVMO como parâmetros.

Por sua vez, não se pode desconsiderar que o baixo desempenho dos rebanhos na região tenha sido creditado justamente à baixa qualidade e à estacionalidade da produção da pastagem nativa (Ramos et al., 1988; Seiffert et al., 1990). Entretanto, a persistência da pastagem nativa no sistema deve ser resultado de algumas características peculiares que seus componentes apresentam. Isto pode ser melhor evidenciado ao considerar-se que a área destinada à bovinocultura representa, em média, $30 \%$ do total da área da propriedade, estando cerca de $60 \%$ desta área ocupada por pastagem nativa (Pillar \& Tcacenco, 1987; Seiffert et al., 1990). Essas áreas são utilizadas de forma intensiva, com lotação de cerca de $3 \mathrm{UA} / \mathrm{ha}$, considerada alta nesse regime de exploração. O solo é considerado ácido, apresentando média a baixa fertilidade, e geralmente não há qualquer tipo de trato cultural. A pastagem nativa surgiu em sucessão à remoção da Floresta Atlântica, que era a cobertura vegetal original. Assim, em média, essas áreas encontram-se em utilização por mais de 40 anos, estando algumas com mais de 100 anos (Pillar \& Tcacenco, 1987). Além disso, essas áreas localizam-se em relevo bastante ondulado, com inclinação média superior a $30 \%$, quando as pastagens tornam-se fundamentais para o controle da erosão. Portanto, a persistência da pastagem nativa sob condições de utilização tão severas, demonstra sua grande adaptação ao ambiente no qual estão inseridas. Nessas condições, a heterogeneidade na composição pode se constituir em um importante instrumento para garantir a longevidade dessas pastagens.

As modificações no ambiente (umidade do solo, fertilidade, pressão de pastejo) podem ser determinantes na manutenção ou evolução das espécies que compõem a pastagem nativa (Pillar, 1988). Em seu estudo, o autor descreve que a umidade do solo foi um fator determinante na distribuição das espécies que compõem as pastagens nativas do Vale do Itajaí. Portanto, intervenções no ambiente devem determinar efeitos na disponibilidade e na qualidade das pastagens. Dessa maneira, antes de interferir no ambiente, deve-se levar em consideração pelo menos alguns dos principais fatores que garantam a persistência e longevidade das pastagens nativas do Vale do Itajaí. Isso seria uma boa forma de garantir a preservação dos recursos naturais, compreendendo o solo, a água, e a vegetação.

\section{CONCLUSÕES}

1. Os parâmetros de qualidade de proteína bruta e de digestibilidade in vitro da matéria orgânica diferem ao longo das estações do ano.

2. O coeficiente de correlação entre os valores de proteína bruta e digestibilidade in vitro da matéria orgânica é baixo nas gramíneas, determinando que os acessos com elevada digestibilidade não necessariamente apresentem altos teores de proteína bruta, sendo o inverso dessa situação também verdadeiro.

3. A utilização de fertilizantes melhora a qualidade de gramíneas, incrementando os valores de proteína bruta e de digestibilidade in vitro.

4. Os melhores valores relativos à digestibilidade in vitro da matéria orgânica ( $>60 \%$ ) foram apresentados pelos acessos de Brachiaria e Digitaria como exóticas, e Axonopus, como acesso nativo.

5. As características de qualidade orgânica (proteína bruta e de digestibilidade in vitro da matéria orgânica), apresentadas pelas espécies exóticas, não são suficientes para justificar a substituição parcial ou total das espécies nativas encontradas nas pastagens do Vale do Itajaí. 


\section{REFERÊNCIAS}

ALMEIDA, E.X. de. Oferta de forragem de capimelefante-anão (Pennisetum purpureum Schum. cv. Mott), dinâmica da pastagem e sua relação com o rendimento animal no alto Vale do Itajaí, Santa Catarina. Porto Alegre : UFRGS, Faculdade de Agronomia, 1997. 112p. Tese de Doutorado.

CHAPMAN, D.F.; LEMAIRE, G. Morphogenetic and structural determinants of plant regrowth after defoliation. In: INTERNATIONAL GRASSLAND CONGRESS, 17., 1993, Palmerston, NZ. Proceedings. Palmerston : NZGA/TGSA/NZSA/ ASAP-QB/NZIAS, 1993. p.95-104.

CONRAD, M.R.; PRATT, A.D.; HIBBS, J.W. Regulation of feed intake in dairy cows. I. Changes in importance of physical and physiological factors with increasing digestibility. Journal of Animal Science, Champaign, v.47, p.54-62, 1964.

HODGSON, J.; OLLERENSHAW, J.H. The frequency and severity of defoliation of individual tillers in set-stocked swards. Journal of the British Grassland Society, Oxford, v.24, p.226-234, 1969.

LEMAIRE, G. The physiology of grass growth under grazing: Tissue turnover. In: INTERNATIONAL SYMPOSIUM ON ANIMAL PRODUCTION UNDER GRAZING, 1997. Viçosa, MG. Proceedings. Viçosa : DZ-UFV, 1997. p.117-144.

MAZZANTI, A.; LEMAIRE, G.; GASTAL, F. The effect of nitrogen fertilization upon the herbage production of tall fescue swards continuously grazed with sheep. 1. Herbage growth dynamics. Grass and Forage Science, Oxford, v.49, p.111-120, 1994.
NELSON, C.J.; MOSER, L.E. Plant factors affecting forage quality. In: FAHEY JUNIOR, G.R. (Ed.). Forage quality, evaluation, and utilization. Madison, Wisconsin : ASA/CSSA/SSSA, 1994. Ch.3, p.115154.

PILLAR, V. de P. Fatores de ambiente relacionados à variação da vegetação de um campo natural. Porto Alegre : UFRGS, 1988. 164p. Tese de Mestrado.

PILLAR, V. de P.; TCACENCO, F.A. As pastagens nativas do Vale do Itajaí e Litoral Norte de Santa Catarina. Florianópolis : EMPASC, 1987. 15p. (EMPASC. Comunicado técnico, 109).

RAMOS, M.G.; SEIFFERT, N.F.; SALERNO, A.R.; ALMEIDA, E.X.; FREITAS, E.G.; DESCHAMPS, F.C. Tabela de composição de alimentos utilizados nos sistemas de produção de leite do Vale do Itajaí e Litoral Norte de Santa Catarina. Florianópolis : EMPASC, 1988. 17p. (EMPASC. Documentos, 95).

SEIFFERT, N.F.; SALERNO, A.R.; RAMOS, M.G Avaliação do sistema de alimentação de vacas leiteiras da região do Vale do Itajaí e Litoral Norte de Santa Catarina. Florianópolis : EMPASC, 1990. 104p. (EMPASC. Documentos, 110).

TCACENCO, F.A. Avaliação de forrageiras nativas e naturalizadas, no Vale do Itajaí, Santa Catarina. Pesquisa Agropecuária Brasileira, Brasília, v.29, n.3, p.475-489, mar. 1994.

TILLEY, J.M.A.; TERRY, R.A. A two-stage technique for the "in vitro" digestion of forage crops. Journal of the British Grassland Society, Oxford, v.18, n.2, p.104-111, 1963. 